\title{
POLITICAS DE PROMOÇÃO INTERNACIONAL DA LÍNGUA PORTUGUESA: AÇÕES NA AMÉRICA LATINA
}

\author{
LANGUAGE POLICIES FOR INTERNATIONAL PROMOTION OF \\ PORTUGUESE LANGUAGE: ACTIONS IN LATIN AMERICA
}

\section{Simone da Costa Carvalho*}

\section{RESUMO}

Este trabalho tem como objetivo traçar um panorama de ações na área de políticas linguísticas relacionadas à promoção e ao ensino do português como língua adicional no Brasil e fora do país, bem como refletir sobre alguns de seus impactos. Primeiramente, são apresentados o conceito de política linguística (COOPER, 1989) e as noções de valor e de mercado linguístico a partir da Nova Economia (OLIVEIRA, 2010). A seguir, apresenta-se um panorama de ações políticas de promoção internacional da língua portuguesa, focalizando naquelas desenvolvidas nos âmbitos do Mercosul e da América Latina. Conclui-se fazendo uma reflexão sobre possíveis implicações dessas ações no ensino e aprendizagem de português como língua adicional, bem como na difusão internacional da língua portuguesa.

Palavras-chave: promoção internacional da língua portuguesa; políticas linguísticas externas; ensino de português como língua adicional.

\section{ABSTRACT}

This paper aims at drawing an overview of actions in the field of language policies related to Portuguese promotion and teaching, as an additional language, in Brazil and abroad, as well as reflecting about some of the impacts of that. First of all, the concept of language planning (COOPER, 1989) will be presented, as well as the notion of value and linguistic market based on the New Economy (OLIVEIRA, 2010). Next, an overview of politic actions for promoting Portuguese Language internationally will be presented, specially the ones developed in Mercosul and Latin America contexts. In the end, possible implications of these actions for the teaching and learning and international promotion of Portuguese as an additional language are discussed.

Keywords: Portuguese language international promotion; international language policy; teaching of Portuguese as an additional language.

\footnotetext{
*UFRGS, Porto Alegre (RS), Brasil.simonecc@hotmail.com
} 


\section{INTRODUÇÃO}

Ao longo de minha experiência como membro da equipe do Programa de Português para Estrangeiros da Universidade Federal do Rio Grande do Sul $(\mathrm{PPE} / \mathrm{UFRGS})^{1}$, e trabalhando com o ensino de Português Língua Adicional ${ }^{2}$ (PLA), sempre acompanhei, juntamente com a equipe do Programa, o desenrolar das ações de política linguística desenvolvidas pelo governo brasileiro nessa área, especialmente o Celpe-Bras (Certificado de Proficiência em Língua Portuguesa para Estrangeiros), exame do qual a UFRGS é posto aplicador. As diretrizes teóricas de tal exame têm influenciado diretamente o ensino de PLA nesse grupo de trabalho, fazendo-o perceber em que proporção ações de políticas linguísticas podem intervir na maneira de entender, ensinar e aprender uma língua. Além disso, o Programa é espaço de formação e de encontro de professores de PLA que têm lecionado ao longo dos anos em diferentes Centros Culturais Brasileiros e Institutos Culturais latino-americanos, bem como em outros continentes, compondo, assim, um ambiente em que os participantes compartilham informações e conhecimentos aprendidos nesses contextos diversos de ensino.

Tais aspectos, relacionados à experiência de formação de professores e docência de PLA, têm se constituído como elementos motivadores para conhecer e refletir sobre as ações de difusão internacional da língua portuguesa. Outro elemento motivador é o debate cada vez mais intenso sobre o multilinguismo e sua relevância no mundo contemporâneo, bem como sobre o modo como o país se insere nesse cenário linguístico mais amplo. Com a projeção brasileira no cenário econômico internacional, demandas crescentes têm emergido na área de ensino de PLA no país, tanto no setor público (no cenário atual, as universidades federais constituem os principais polos de ensino, pesquisa e formação de professores nesse campo ${ }^{3}$ ) quanto no setor privado. Nunca antes o Brasil testemunhou um interesse tão grande

1 O PPE/UFRGS foi criado em 1994 e tem como um de seus principais objetivos a formação de professores-pesquisadores com foco na reflexão sobre as práticas docentes e de desenvolvimento de pesquisa na área de ensino e de avaliação de PLA. No âmbito do grupo, vêm sendo realizados diversos trabalhos de pesquisa em nível de graduação e pós-graduação relacionados ao CelpeBras, à produção de materiais didáticos e a práticas de ensino e de avaliação no campo do ensino à distância.

$2 \mathrm{O}$ termo língua adicional, preferido neste texto aos termos lingua estrangeira ou segunda língua, ressalta a adição da língua portuguesa a outras que o indivíduo já possui em seu repertório e baseia-se em uma visão que entende a atuação dos sujeitos e a comunicação na vida contemporânea como transcendentes às fronteiras físicas nacionais, de modo que a distinção entre nativo/estrangeiro ou primeira/segunda língua perde seu sentido (conforme SCHLATTER \& GARCEZ, 2009).

3 Carvalho \& Schlatter (2011) oferecem um breve panorama dos grupos de ensino e pesquisa de PLA no Brasil, bem como de trabalhos acadêmicos na área. 
por parte de estrangeiros em aprender a língua falada no país ${ }^{4}$. Esse conjunto de aspectos suscita reflexões sobre o protagonismo que o Estado brasileiro tem tido na promoção da língua em nível internacional e também na construção de uma cultura linguística interna mais positiva e diversa.

Segundo o Ethnologue (LEWIS, 2009), a língua portuguesa é a sétima mais falada no mundo, além de ocupar a quinta posição em número de usuários na Internet, de acordo com a pesquisa Top Ten Languages Internet Stats ${ }^{5}$ (2010), sendo que o Brasil responde por $85 \%$ dos falantes de língua portuguesa do mundo. Mesmo diante desse quadro numérico favorável, o Estado brasileiro teve, durante muitos anos, uma ação inexpressiva tanto na promoção internacional do português quanto na construção de uma cultura linguística interna mais positiva, conforme discutiu Faraco (2008). Esse quadro, no entanto, passa por um período de transformações, com a criação e manutenção de políticas de língua protagonizadas pelo Estado e também por outros atores sociais, que apontam para uma maior circulação e valorização da(s) língua(s). Tais fatos e aspectos levam a refletir sobre que representações temos da língua portuguesa, interna e externamente, e quais seriam as razões para a nãoassunção, por parte do Brasil, de um maior protagonismo na difusão internacional de sua língua e cultura.

Levando em conta as questões citadas, um dos objetivos do presente texto é contribuir para informar e auxiliar na reflexão sobre as políticas brasileiras de difusão internacional do português, e, por conseguinte, pôr em discussão a importância dessas ações no âmbito do ensino e aprendizagem de PLA e da promoção internacional da língua. Para isso, num primeiro momento, apresento os conceitos chave da área de política e planificação linguística que serviram de base para a realização deste trabalho, além de discutir brevemente sobre as ações de política linguística da perspectiva de valor e de mercado. Em seguida, traço um panorama com algumas das ações que vêm sendo desenvolvidas na área de políticas linguísticas para a difusão e a promoção da língua portuguesa no cenário internacional -, tanto geridas pelo Estado, como por outros atores sociais. Destaco o exame Celpe-Bras e algumas iniciativas nos âmbitos do MERCOSUL e da América Latina. Por fim, faço

4 Entre 2009 e 2011, as permissões temporárias de trabalho concedidas a estrangeiros no Brasil aumentaram 65\% (passando de 40.200, em 2009, a 66.400, em 2011) enquanto o número de vistos de estudante cresceu em 34\% (passando de 15.700, em 2009, a 21.000, em 2011), conforme Martín \& Bedineli (2012). Outro exemplo desse crescimento é o número de candidatos ao Celpe-Bras, que passou de 1.155 (em 2000) para 6.139 (em 2010). Seguindo a mesma tendência, os centros culturais brasileiros no exterior custeados pelo MRE recebiam cerca de 17,5 mil alunos em 2004, e em 2010 contaram com 31,7 mil estudantes (conforme FOREQUE, 2011).

5 Disponível em <http://www.internetworldstats.com/stats7.htm>. Acesso em 10 jun. 2012. 
uma breve reflexão sobre os possíveis impactos dessas ações de política linguística na difusão internacional da língua portuguesa, no ensino e aprendizagem de PLA, bem como nas relações entre as línguas no MERCOSUL e dentro do próprio país.

\section{POLÍTICA E PLANIFICAÇÃO LINGUíSTICA: INTERVENÇÃO SOBRE A(S) LÍNGUA(S)}

O campo da política e planificação linguística ${ }^{6}$ (PPL), como matéria científica, nasceu na segunda metade do século XX de contextos associados ao plurilinguismo e a mudanças políticas nos estatutos das línguas envolvidas, com vistas a gerenciar esse plurilinguismo (CALVET, 2007; RICENTO, 2000), como foi o caso de vários países africanos e asiáticos que, a partir da década de 50, entraram em processo de descolonização. O contexto deflagrava oficialmente a necessidade de agir sobre as linguas e foi exatamente esse aspecto que fez surgir o campo da PPL.

Os conceitos de política e planificação linguística foram primeiramente sistematizados na década de 1960 pelo linguista Einar Haugen (1966), sendo assim articulados por Oliveira (2004):

Política linguística é o conjunto de decisões que um grupo de poder, sobretudo um Estado (mas também uma Igreja ou outros tipos de instituições de poder menos totalizantes), toma sobre o lugar e a forma das línguas na sociedade, e a implementação destas decisões.

Planificação linguística são propostas para modificar a realidade linguística - do status de uma língua em relação a outra, ou de aspectos da sua forma - e se referem ao futuro da relação entre as línguas. Um processo de planificação linguística posta em marcha passa a ser uma política linguística (p. 38, grifos no original).

Cooper (1989), participante de um momento posterior de desenvolvimento da área, analisa o conceito de PPL elaborado por diferentes autores de modo a esboçar sua própria definição: "políticas linguísticas se referem aos esforços deliberados para influenciar o comportamento de outros no que concerne à aquisição, estrutura ou alocação funcional de seus códigos linguísticos" (p. 45). Em seu conceito, o autor abre espaço para a ação de outros agentes além do Estado, e

6 Diferentes designações têm sido usadas para definir o conceito de política e planificação linguística. Do mesmo modo, no Brasil, não existe ainda consenso quanto ao termo. Dentre os termos utilizados na literatura internacional especializada estão (conforme GARCÍA \& MENKEN, 2012, p. 249): planificação linguística (COOPER, 1989; KAPLAN \& BALDAUF, 1997); política linguística (PL) (RICENTO, 2006; SHOHAMY, 2006), política e planificação linguística (PPL) (HORNBERGER, 2006). 
também para o fato de que as PL ocorrem em diferentes níveis, que vão do nível micro ao macrossocial. Cooper também é responsável por introduzir as políticas de aquisição (aquisition planning) como um terceiro foco do campo de estudo, tornando o âmbito do ensino objeto de pesquisa da PPL (p. 33).

As intervenções sobre as línguas podem ser de dois tipos: sobre o corpus, quando se trata de propostas de intervenção sobre a forma de uma determinada língua, e sobre o status, quando é relativa à promoção de determinada língua num contexto de plurilinguismo. Um exemplo de intervenção sobre o status é o investimento que certos países fazem na promoção de uma língua. Uma noção surgida nos anos de 1980 é a chamada indústria das línguas (Calvet, 2007), relacionada à criação de objetos (dicionários, softwares, bases de dados, etc.) e produtos linguísticos (referentes à neologia, à terminologia) num cenário de pesquisa multidisciplinar que envolve tecnologias da informação e o cruzamento de áreas como informática, ciências cognitivas e linguística. Um exemplo de ação desse tipo é um dos atuais projetos do Instituto Internacional da Língua Portuguesa (IILP), o Vocabulário Ortográfico Comum da Lingua Portuguesa (VOC), que tem por objetivo a elaboração de um instrumento linguístico comum para a Comunidade dos Países de Língua Portuguesa (CPLP), abrangendo léxico de áreas especializadas. Como exemplo de intervenção sobre o corpus, podemos citar o Acordo Ortográfico, também firmado no âmbito da CPLP, cujo intuito é unificar as duas ortografias existentes da língua portuguesa. Dentre os objetivos da iniciativa estão estimular a troca cultural entre países e incrementar as taxas de letramento dentro da CPLP, além de promover uma maior circulação de materiais produzidos no idioma, de modo a favorecer uma abertura do mercado editorial.

A intervenção sobre as situações linguísticas necessita geralmente de meios para se materializar, representados pelo equipamento das línguas, do qual fazem parte a escrita, o léxico (que envolve a terminologia e a criação de neologismos) e a padronização (em caso de uma língua sofrer dialetação, pode instituir-se a necessidade de escolher um padrão). Outro aspecto relevante na intervenção sobre as situações linguísticas é o ambiente linguístico, representado pela presença e circulação da língua na vida de uma comunidade, nos anúncios, na internet, em campanhas públicas, etc., que, por interferir na presença simbólica da(s) língua(s), também representa um importante instrumento do planejamento linguístico.

Quando um Estado ou grupo de poder quer impor uma decisão, normalmente faz uso da lei, que é um dos grandes instrumentos do planejamento linguístico. Conforme Calvet (2007), as leis linguísticas podem tratar da forma, do uso ou da defesa das línguas. As leis que definem a forma podem interferir na escrita e no 
léxico (como é o caso do já citado Acordo Ortográfico em vigor na CPLP). As leis que tratam do uso da língua normalmente lidam com seu status, e definem em que espaços e em quais atividades uma língua deve (ou não) ser usada (por exemplo, a Lei Municipal N. 1136/2009 de Santa Maria de Jetibá, que tornou a língua pomerana cooficial à língua portuguesa nesse município do estado do Espírito Santo77). Já as leis que se ocupam da defesa das línguas podem versar sobre a proteção ou a promoção internacional de um idioma (tomemos como exemplo o Projeto de Lei Federal 1676/19998, que restringe o uso de estrangeirismos no Brasil e dispõe sobre "a promoção, a proteção, a defesa e o uso da Língua Portuguesa").

Numa abordagem que vai além dos aspectos instrumentais da PPL, representantes da chamada "abordagem crítica" (como HORNBERGER, 2006; RICENTO, 2006), evidenciam a natureza inter e transdisciplinar da PPL, influenciada pelas teorias pós-modernistas na área das ciências sociais e humanas. Os estudos afiliados a essa abordagem levam em conta a ideologia, a ecologia e a agentividade na busca por compreender e explicar como funcionam e quais são os efeitos das PPL. A partir dessa nova perspectiva, o foco das pesquisas ampliouse e passou a abranger não apenas as macropolíticas (representadas, em grande parte, pelas políticas nacionais de educação), que ainda representam o principal tema dos estudos na área, mas também as ações de nível micro, que correspondem à apropriação individual e/ou institucional das políticas propostas. Segundo Baldauf (2006, p. 155),

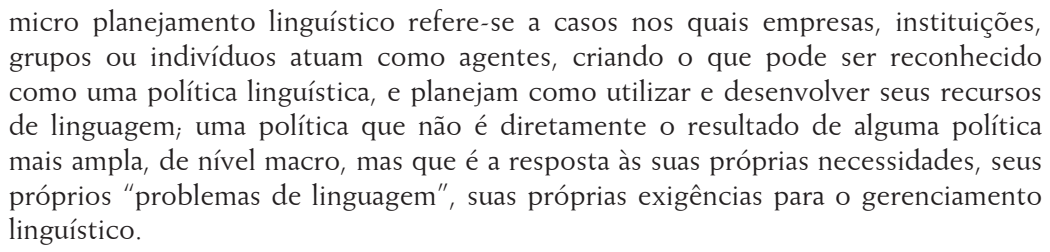

Assim, levando-se em conta o modo como diferentes atores sociais atuam na implementação de uma política linguística, estudos mais recentes destacam a centralidade do papel ocupado pelo professor no desenvolvimento de políticas

7 A lei assegura que a língua cooficializada esteja também presente nos órgãos de administração pública, na produção de toda e qualquer documentação pública, nas campanhas publicitárias institucionais, entre outros, além de estimular sua presença na escola e nas instituições de ensino do município.

8 O Projeto, proposto pelo então deputado federal Aldo Rebelo, foi aprovado com modificações no texto original e publicado em 2008. Etapas de tramitação do projeto estão disponíveis em $<$ http://www.camara.gov.br/proposicoesWeb/fichadetramitacao? idProposicao $=17069>$. Acesso em 20 de set. 2012. 
linguísticas de aquisição (GARCÍA \& MENKEN, 2010). Se considerarmos que as políticas de aquisição afetam as políticas de corpus e status, dada a interligação entre os três eixos da PPL, as ações concebidas na área da educação são essenciais no gerenciamento das línguas.

Foram apresentados nesta seção alguns conceitos e aspectos teóricos que deram base a este trabalho. A seguir, apresento uma perspectiva que analisa a situação das línguas e seu gerenciamento como imersas em um mercado linguístico.

\section{0 VALOR DA(S) LÍNGUA(S)}

Oliveira (2010) analisa os mercados linguísticos na América do Sul a partir de uma teoria sobre o peso das línguas, definida por ele como "um instrumento para analisar e formular políticas linguísticas tendo por base a situação de uma língua dentro de um mercado linguístico" (p. 21). Segundo o autor, uma das grandes forças propulsoras no cenário das transformações globais que tem influenciado a organização sociolinguística em escala mundial é a chamada Nova Economia ou Sociedade do Conbecimento, constituída a partir de mudanças sofridas pelo capitalismo desde os anos 1970 e de modo mais pungente a partir dos anos 1990. O novo paradigma, também chamado de "modo de produção just-in-time", contrapõe-se ao antigo modo fordista ${ }^{9}$, e prioriza modelos de acumulação mais flexíveis - direcionados à produção de pequenas quantidades de diversos modelos e não mais de grandes quantidades de um mesmo produto. Nesse modo de produção, a comunicação e a informação fazem parte de todo o processo produtivo e mantêm relações complexas com a inovação tecnológica e produtiva.

Esse novo paradigma econômico tem gerado demandas que apontam, em primeiro lugar, para uma maior atenção às línguas, e, em segundo lugar, para uma outra forma de gerir essas línguas, caracterizada por uma maior abertura ao multilinguismo e seu cultivo. Como afirma o autor,

[...] países que nunca trataram da questão das línguas, apressam-se em elaborar programas.[...] Oficializam-se novas línguas, reformam-se os sistemas de ensino de línguas estrangeiras, novas línguas lutam para entrar nos curricula, novos e grandes bancos de dados de línguas são montados e financiados (p. 22).

9 No modelo fordista, o trabalho é feito em etapas e em grandes unidades de produção, nas quais são produzidas muitas unidades de um mesmo produto, o que garantiria menor custo e maiores ganhos de produtividade. Uma empresa que adotasse esse tipo de produção necessitava de empregados fixos, que executassem movimentos rotineiros durante todo o dia, e que preferentemente trabalhassem em silêncio, para garantir a eficiência na produção. 
Outra característica dessa nova configuração é a composição de redes e agrupamentos (em articulações que podem ocorrer dos planos micro ao macro, tais como os agrupamentos de pessoas, empresas, instituições, países) formados para responder a esse processo da economia de escala global. Associações de países, como, por exemplo, IBAS, BRICS, MERCOSUL e UNASUL, surgidas nos últimos 25 anos, têm trazido consigo a necessidade de atender à formação de um cidadão multifacetado, capaz de lidar com as novas exigências de mercado que se colocam. O Mercado Comum do Sul (MERCOSUL) constitui um grupo de países ${ }^{10}$ instituído em torno de objetivos comuns de cooperação econômica, científica e tecnológica. Apesar das dificuldades de pôr em prática o projeto de integração, o bloco forma o terreno onde se desenrolam diversas ações de política linguística ${ }^{11}$, muitas das quais protagonizadas por atores sociais não ligados a órgãos governamentais. Várias dessas ações têm sido resultado de esforços em grande parte protagonizados por Brasil e Argentina, países que têm um histórico mais longo de cooperação oficial por meio de relações bilaterais ${ }^{12}$. A parceria entre os dois países ampliou os espaços de atuação do português e do espanhol como línguas adicionais (em 2005, os governos brasileiro e argentino assinaram o Protocolo para a promoção e o ensino do espanbol e do português como segundas línguas), permitindo o surgimento de um mercado crescente de ensino dos dois idiomas oficiais nos países-membros e associados, e deslocou o lugar do inglês como língua adicional praticamente hegemônica nos currículos escolares de ambos os países.

O contexto de cooperação do bloco tem gerado demandas que estimulam a aprendizagem de línguas majoritárias e locais, incentivando a criação de iniciativas por parte do Estado e de outros atores sociais. Em outros casos, ocorre também o movimento contrário, como quando ações de PL geram demandas de ensino/ aprendizagem de idiomas. Em outras palavras, o cenário regional configurase a partir dessa dinâmica entre demandas e ações que se correlacionam e se retroalimentam, bem como produzem mudanças no ensino, na aprendizagem e também no gerenciamento das línguas na Região. Oliveira (2010) também chama a atenção para outro elemento presente na dinâmica das relações linguísticas entre países do MERCOSUL, a reciprocidade. Segundo o autor, a trajetória de parcerias

10 O MERCOSUL foi criado em 1991, com a assinatura do Tratado de Assunção por Argentina, Brasil, Paraguai e Uruguai. São países associados: Chile, Bolívia, Peru, Equador, Colômbia e Venezuela.

11 Conforme Diniz (2010), a própria configuração do MERCOSUL, por constituir um gesto político do Estado brasileiro em relação à inclusão do português do Brasil em um espaço geopolítico transnacional, pode ser vista como o marco de um novo período no processo de gramatização brasileira, constituindo uma posição de autoria para o Estado/cidadão brasileiro.

12 Cristofoli (2010) investiga políticas e ações bilaterais no plano educacional entre Brasil e Argentina. 
bilaterais entre Brasil e Argentina, bem como a ação brasileira de promulgar a Lei N. 16.161 (que tornou o espanhol língua de oferta obrigatória no ensino médio regular do país a partir de 2010) deu visibilidade ao idioma espanhol no bloco, o que permitiu um novo posicionamento da Argentina quanto ao gerenciamento de sua língua, levando o país a desenvolver ações como o CELU (Certificado de Español Lengua y Uso), resultado de uma parceria entre universidades brasileiras e argentinas (como explicitado mais adiante). Em contrapartida, a Argentina tornou obrigatória a oferta do português na escola secundária pela Lei N. 26.468 (dezembro de 2008) ${ }^{13}$.

Outras ações e programas que integram o contexto de cooperação latinoamericano são os intercâmbios acadêmicos (tais como o Programa ESCALA Estudantil e o MARCA), programas de trabalho e pesquisa entre IES de diferentes países (como é o caso do CEPI), acordos de cooperação educacional, como o PBEIF - escolas de fronteira ${ }^{14}$. Do mesmo modo, no Brasil, outras demandas internas, além do próprio MERCOSUL, têm requerido dos brasileiros a aprendizagem de línguas adicionais, como é o caso do programa de mobilidade acadêmica internacional Ciência sem Fronteiras ${ }^{15}$.

Nesta seção busquei discutir sobre a Nova Economia como criadora de demandas que movimentam o mercado linguístico no âmbito do MERCOSUL e que tem gerado um reposicionamento dos países e atores sociais na gestão das línguas no bloco ${ }^{16}$. A seguir, apresento algumas iniciativas protagonizadas pelo

13 Cristofoli (2010) analisa os avanços e dificuldades de implementação das decisões referentes às políticas públicas curriculares no âmbito das relações entre Brasil e Argentina (mais especificamente no Rio Grande do Sul e na Província de Córdoba). A autora aponta o lapso existente entre as políticas oficiais propostas e suas instâncias de implementação, expresso, entre outros aspectos, pela falta de planejamento na execução das políticas, pelos problemas de formação docente e pela falta de professores para que se possam colocar em prática as leis em ambos os países.

14 As ações citadas nesse parágrafo fazem parte do panorama de iniciativas apresentado a seguir.

15 Lançado em 2011, o programa coordenado pela Capes e pelo CNPq busca "promover, de maneira acelerada, o desenvolvimento tecnológico e estimular os processos de inovação no Brasil por meio da mobilidade internacional docente, discente de graduação e pós-graduação, de pós-doutorandos e pesquisadores brasileiros, estimulando a inserção das pesquisas feitas nas instituições brasileiras às melhores experiências internacionais" (http://www.capes.gov.br/bolsas/bolsas-no-exterior/ ciencia-sem-fronteiras). O programa, que já possui parcerias com instituições da Alemanha, Austrália, Bélgica, Canadá, Coreia, Espanha, Estados Unidos, França, Holanda, Itália, Portugal e Reino Unido, tem por meta oferecer 75 mil bolsas até 2015. A exigência de comprovação de proficiência nas línguas dos países de destino pelos candidatos tem lançado demandas internas de formação linguística e tem suscitado a atenção do governo federal para a questão do ensino de línguas adicionais no ensino regular no Brasil.

16 Diniz $(2010,2012)$ oferece uma outra perspectiva dessa mudança, focalizando sobre como são concebidos discursivamente esse novo posicionamento na gestão das línguas e a própria promoção internacional da língua portuguesa. 
governo brasileiro e outros atores sociais no campo das políticas de promoção e difusão do português como língua internacional ${ }^{17}$.

\section{REDE BRASILEIRA DE ENSINO NO EXTERIOR (RBEX) ${ }^{18}$}

A Rede Brasileira de Ensino no Exterior (RBEx) é formada pelos Centros Culturais do Brasil (CCB), Institutos Culturais bilaterais (IC) e Leitorados brasileiros, sendo gerenciada pela Divisão de Promoção da Língua Portuguesa (DPLP) do Ministério das Relações Exteriores (MRE).

Os CCB, cujas atividades estão relacionadas ao ensino do português, à difusão da literatura e cultura brasileiras, constituem o principal instrumento público de promoção do português falado no Brasil. Existem, hoje, 12 CCB no continente americano, 3 na Europa e 6 na África, totalizando 21 entidades.

Os IC são organismos de direito privado sem fins lucrativos e estão presentes nas capitais dos seguintes países: Argentina, Colômbia, Costa Rica, Equador, Itália, Uruguai e Venezuela. São entidades autônomas, mas cumprem seu trabalho em coordenação com as Missões diplomáticas e consulares brasileiras do seu local de sede. Todos os CCB e IC são ou estão se tornando postos aplicadores do CelpeBras (apresentado a seguir).

Já a rede de leitorados reúne professores especialistas em língua portuguesa, literatura e cultura brasileiras, atuando em conceituadas universidades estrangeiras. Os professores leitores são selecionados pelo MRE e pela Coordenação de Aperfeiçoamento de Pessoal de Nível Superior (CAPES), agência do Ministério da Educação (MEC); em uma segunda etapa, a seleção é feita pela própria universidade que vai receber o professor leitor. Atualmente, há 64 leitorados, em 41 países ${ }^{19}$.

Embora a RBEx ocupe papel de destaque na difusão internacional do português, seus setores ainda constituem um território pouco explorado em termos de pesquisa acadêmica. Da perspectiva do ensino, o trabalho desenvolvido nesses setores é bastante diverso daquele realizado por grupos de ensino e pesquisa de PLA no Brasil (principais polos de ensino de PLA no país), no que se refere a aspectos como formação de professores e elaboração de materiais didáticos. Dentre algumas das pesquisas desenvolvidas na área, Costa (em preparação) investiga como ocorre a formação de docentes em serviço em um IC sul-americano; Diniz (2012) analisa

17 Ações de difusão internacional da língua portuguesa são também apresentadas em Carvalho \& Schlatter (2011).

18 Dados e informações apresentados nesta subseção encontram-se em BRASIL-MRE (2011).

19 Fonte: <http://www.dc.mre.gov.br/lingua-e-literatura/leitorados > . Acesso em 15 mar. 2012. 
a organização e os processos de representação dos diferentes setores da RBEx, usando como referencial teórico a História das Ideias Linguísticas.

\section{PROGRAMA DE ESTUDANTES CONVÊNIO DE GRADUAÇÃO (PEC-G) E DE PÓS-GRADUAÇÃO (PEC-PG)}

Criado em 1965 com o objetivo de formar recursos humanos de países em desenvolvimento, o PEC-G possibilita a estudantes de nações com as quais o Brasil mantém acordos de cooperação cultural e/ou educacional e/ou de ciência e tecnologia estudar nas Instituições de Ensino Superior (IES) brasileiras. Atualmente, 45 países participam do PEC-G: 20 da África, 14 da América Central, o Timor Leste, além de 11 países sul-americanos ${ }^{20}$. Já através do PEC-PG, são oferecidas vagas em cursos de Mestrado e Doutorado em universidades brasileiras, incluindo bolsas de estudos de doutorado, oferecidas pela CAPES e pelo Conselho Nacional de Desenvolvimento Científico e Tecnológico $(\mathrm{CNPq})^{21}$. A obtenção de nível intermediário no exame Celpe-Bras é requisito mínimo de proficiência linguística à candidatura aos Programas PEC-G e PEC-PG (em vigor desde 1999), o que se reflete no número de candidatos ao exame, bem como na oferta e nas práticas de ensino para preparação dos estudantes, conforme veremos a seguir.

\section{CERTIFICADO DE PROFICIÊNCIA EM LÍNGUA PORTUGUESA PARA ESTRAN- GEIROS (CELPE-BRAS)}

A partir da década de 1990, o número crescente de intercâmbios econômicos, culturais e científicos do Brasil com outros países e uma procura maior por cursos de graduação e pós-graduação no país ampliaram a necessidade de ter-se uma referência de proficiência de língua portuguesa. Com base nessa demanda crescente, o MEC convocou em 1993 uma Comissão Técnica composta de estudiosos da área de PLA, que veio a elaborar o exame Celpe-Bras. Segundo Scaramucci (2006),

20 Fonte: <http://www.dce.mre.gov.br/pec/G/historico.html> . Acesso em 15 mar. 2012.

21 No período de 2003 a 2010, 4.300 estudantes africanos de graduação (de 20 países), além de 237 pós-graduandos (de 14 nações da África) vieram estudar no Brasil, principalmente através dos Programas PEC-G E PEC-PG (BRASIL-MRE, 2011). Já no âmbito da América Latina, os dois programas trouxeram ao país, entre 2001 e 2011 , cerca de 1.173 estudantes de graduação e 1.194 de Pós-Graduação. <http://www.dce.mre.gov.br/pec/G/historico.html> e <http://www. dce.mre.gov.br/pec/PG/historico.html>. Acesso em 24 set. 2012. 
não se pode deixar de reconhecer que esse objetivo foi impulsionado, em grande parte, pelo plano de integração MERCOSUL. (...) E havia também o reconhecimento de seu potencial (re)direcionador do ensino/aprendizagem de PLE/L2, uma vez que esse ensino ainda se pauta, em grande parte, em abordagens com foco na forma e não no uso da linguagem (p. 271).

O exame, aplicado no Brasil e no exterior desde 1998 com o apoio do MRE22, passou à responsabilidade do INEP (Instituto Nacional de Estudos e Pesquisas Educacionais Anísio Teixeira) ${ }^{23}$ a partir de 2009. Em 2011, foi aplicado em 21 instituições no Brasil e em outros 29 países, sendo que o MEC projeta um aumento substancial na abrangência do exame no futuro, dado o interesse crescente de credenciamento de novos postos aplicadores no exterior ${ }^{24}$.

A certificação é pré-requisito para ingresso de estudantes estrangeiros em cursos de graduação e pós-graduação em universidades brasileiras, além de ser exigida para validação de diplomas de profissionais de outros países que desejem trabalhar no Brasil (como é o caso do Conselho Federal de Medicina, que exige o certificado desde 2001 para inscrever médicos estrangeiros que queiram aperfeiçoarse e/ou atuar no país).

O Celpe-Bras avalia o uso da linguagem de modo mais amplo, não focalizando em áreas específicas como a acadêmica e/ou a profissional, como ocorre com outros exames de proficiência de língua adicional. Sendo um exame de desempenho, no qual as habilidades são avaliadas de modo integrado, o instrumento busca avaliar diretamente a capacidade que quer aferir (no caso, o uso da língua) por meio de tarefas que envolvem compreensão oral, leitura, produção oral e produção escrita. Baseado em uma visão da linguagem como "ação conjunta de participantes com um propósito social" (BRASIL, Manual do Candidato, 2006) e no convite ao uso da linguagem através de tarefas que levam em conta o contexto da interação, o exame tem exercido um papel muito importante como redimensionador do ensino e aprendizagem de PLA.

Segundo Schlatter et al. (2009), dentre os impactos do exame estão o incentivo à busca por formação de professores, a elaboração e seleção de materiais didáticos direcionadas à compreensão e produção de texto, e, por fim, práticas de ensino mais voltadas ao contexto de interação e menos estruturalistas (conforme

22 A trajetória de implementação do Celpe-Bras desde sua criação, bem como o construto teórico do exame são apresentados em Schlatter et al. (2009).

23 Em dezembro de 2011, através da Chamada Pública № 12/2011, foi selecionada pelo INEP uma nova Comissão Técnica responsável pela elaboração do Exame e pela definição dos critérios de aplicação.

24 Conforme notícia publicada no Portal do INEP: <http://portal.inep.gov.br/visualizar/-/asset publisher/6AhJ/content/america-latina-tem-o-maior-numero-de-participantes-no-celpe-bras? re $\overline{\mathrm{di}}$ rect $=$ http\%3a\%2f\%2fportal.inep.gov.br\%2f $>$. Acesso em 28 ago. 2012. 
Schlatter, 2006; Scaramucci, 2006; Li, 2009). O Celpe também apresenta reflexos na cultura de preparação dos candidatos, como demonstra o número crescente de alunos buscando uma preparação mais específica para o exame. Além desses aspectos, o fato de ser uma avaliação de desempenho demanda também a importância de investir na capacitação de profissionais especializados envolvidos na elaboração, aplicação e correção do exame, para que os efeitos de redirecionamento desejados sejam alcançados ${ }^{25}$.

Várias pesquisas acadêmicas têm se dedicado a analisar o Celpe-Bras e seus impactos, contribuindo para a construção do campo de pesquisa sobre avaliação na área de línguas adicionais no Brasil ${ }^{26}$, no qual participam pesquisadores de diferentes universidades brasileiras. Segundo Carvalho \& Schlatter (2011), um dos grandes estímulos para esse intercâmbio é a reunião de profissionais oriundos de diferentes universidades brasileiras e também dos CEB e IC para a correção presencial do Celpe-Bras, que ocorre duas vezes ao ano. Como afirmam as autoras, esses encontros propiciam aberturas para o diálogo e a troca de ideias entre profissionais de PLA, além de uma formação continuada a respeito dos pressupostos teóricos do exame: "essa ação continuada torna-se, assim, terreno fértil para a atualização e mudanças nas práticas de ensino e na elaboração de materiais didáticos e para possíveis parcerias de pesquisa na área" (p. 270).

Cabe destacar que o exame serviu de referência na elaboração de dois outros instrumentos de avaliação de proficiência: o Certificado de Proficiência em Libras, no Brasil, e o Certificado de Español - Lengua y Uso (CELU), na Argentina, que compartilham com o Celpe-Bras os pressupostos teóricos, a visão de linguagem e os objetivos. O exame argentino foi concebido por meio de uma parceria entre as comissões brasileira e argentina responsáveis pelos exames nos dois países. O CELU e o Celpe, como instrumentos de avaliação de proficiência em uso da língua, buscam também "afirmar as variedades brasileira e rio-platense na elaboração de instrumentos de avaliação de proficiência em língua portuguesa e espanhola", como afirmam Schlatter et al. (2009), com base nos contextos de intercâmbios acadêmicos e econômicos entre o Brasil e a Argentina. Segundo as autoras, os dois exames têm sido parâmetros de referência para o desenvolvimento de currículos e de materiais didáticos, bem como têm promovido a atualização dos professores, servindo como norteadores de mudanças no ensino e na definição de parâmetros de proficiência em uso da língua.

25 Desde 2011 têm ocorrido encontros de capacitação de colaboradores e elaboração de itens para incrementar o Banco Nacional de Itens do Celpe-Bras. A seleção de colaboradores é feita por meio de chamada pública e conta com mestres e doutores na área de PLA e de Linguística Aplicada.

26 Carvalho \& Schlatter (2011) oferecem um panorama de temas e pesquisas desenvolvidos na área de PLA no Brasil. 
Da perspectiva da História das ideias linguísticas, outro possível impacto do exame, de acordo com Zoppi Fontana (2009) e Diniz (2010), é a imagem do português como língua transnacional - representada em determinados instrumentos linguísticos como o exame Celpe-Bras e materiais didáticos de PLA - que tem afetado o imaginário brasileiro sobre a língua portuguesa falada no país, conferindo-lhe uma noção diferente de valor. Zoppi Fontana (2009) insere a criação do exame como um dos acontecimentos linguísticos do "novo período de gramatização brasileira" iniciado nos anos 90, analisando-o como evento que colabora para ressignificar o lugar da língua brasileira no mundo, visto que esses novos significados se refletem e materializam nas práticas de políticas linguísticas governamentais e também em práticas da sociedade civil, como no campo editorial e acadêmico.

\section{INSTITUTO INTERNACIONAL DA LÍNGUA PORTUGUESA (IILP)}

Identificado como o primeiro instrumento institucional da Comunidade dos Países de Língua Portuguesa (CPLP) ${ }^{27}$, o IILP teve sua sede instituída em 2002, na cidade da Praia (Cabo Verde) após anos de discussão sobre a criação de um instituto visando a articulação da lusofonia. Durante quase uma década, o organismo foi apontado como ineficiente, principalmente por sua falta de definição quanto ao espaço de atuação e à suposta incapacidade diante de ações como as conduzidas pelo Instituto Camões ${ }^{28}$ (conforme FARACO, 2008). Desde 2010, no entanto, a atual direção do Instituto investe em formas mais estratégicas de gerir as questões linguísticas no âmbito da CPLP, buscando discutir a lusofonia além do tradicional binômio Brasil-Portugal e promover um diálogo mais amplo entre os países lusófonos. O diretor da entidade, Gilvan de Oliveira, destaca que a crescente procura que a língua portuguesa vem sofrendo não é suficiente para projetar o idioma, e acredita que "é preciso acelerar a presença do Português nos blocos económicos regionais', como União Europeia, Mercosul ou ASEAN, porque

27 Criada em 1996, a CPLP é composta por oito países: Brasil, Angola, Cabo Verde, Guiné-Bissau, Moçambique, Portugal, São Tomé e Príncipe e Timor-Leste. Entre os objetivos da entidade estão a articulação político-diplomática entre os países-membros, a cooperação econômica, social, cultural, jurídica e técnico-científica, e a promoção e difusão da Língua Portuguesa. Uma das ações articuladas no âmbito da CPLP foi o Acordo Ortográfico, que tem por objetivo unificar as duas ortografias existentes da língua portuguesa, entrando em vigor de forma plena em janeiro de 2013.

28 O Instituto Camões foi criado pelo governo de Portugal em 1992 como órgão de promoção da língua oficial desse país, e tem marcado presença internacional através de uma intensa atuação em universidades estrangeiras, por meio de bibliotecas equipadas e distribuição de bolsas de estudo (FARACO, 2008). 
'exercem pressão sobre as Nações Unidas', dado que 'envolvem toda a sociedade transversalmente" ${ }^{\prime \prime 29}$. As ações do Instituto têm como base o Plano de Ação de Brasília para a Promoção, a Projeção e a Difusão da Língua Portuguesa, documento elaborado durante a I Conferência Internacional sobre o Futuro da Lingua Portuguesa no Sistema Mundial (Brasília, 2010), que definiu as linhas de trabalho do instituto de 2010 a 2012. Com vistas a discutir as quatro áreas estratégicas previstas no documento e preparar os países da CPLP para a II Conferência Internacional (prevista para 2013, em Lisboa), o instituto programou quatro colóquios, que vêm ocorrendo desde 2011 em diferentes países da Comunidade. O primeiro foi o Colóquio de Maputo (2011) que versou sobre a diversidade linguística e questões ligadas às 339 línguas faladas nos países da CPLP. Ocorrido na cidade da Praia (2011), o Colóquio Internacional sobre a Lingua Portuguesa nas Diásporas recebeu especialistas que apresentaram suas experiências sobre o ensino do português no exterior e nos contextos de diáspora. $\mathrm{O}$ terceiro evento, denominado A Lingua Portuguesa na Internet e no Mundo Digital (Guaramiranga, 2012), discutiu a unificação do português na Internet, reunindo especialistas do setor governamental, ligados às instituições públicas de gerenciamento da internet e da informação, além de especialistas do setor privado e pesquisadores acadêmicos. Por fim, foi realizado o Colóquio Internacional de Luanda sobre o Português nas Organizações Internacionais (2012) para debater a situação do português na ONU e em outros blocos regionais, uma das questões em foco na atual coordenação do IILP. Outro projeto em andamento no Instituto é o Vocabulário Ortográfico Comum da Lingua Portuguesa (VOC), cujo objetivo é a constituição de um instrumento linguístico comum aos países da CPLP, envolvendo o léxico de áreas especializadas. Essa iniciativa indica um reconhecimento, pela entidade, da importância dos equipamentos linguísticos como estratégicos para a circulação e difusão das línguas.

\section{AÇÕES NO MERCOSUL E NA AMÉRICA LATINA}

Composto pelos Estados partes Argentina, Brasil, Paraguai e Uruguai, e Estados associados Chile, Bolívia, Peru, Equador, Colômbia e Venezuela, o MERCOSUL constitui um espaço político comum no qual os países do grupo buscam ampliar seus mercados nacionais através da integração, essencial para acelerar seus processos de desenvolvimento econômico. Reconhecendo-se desde

29 Maior presença do Português nos blocos económicos "pode ajudar" língua a "chegar" à ONU - diretor do IILP. Sapo.mz. Notícias, 31/08/2011. Disponível em <http://noticias.sapo.mz/lusa/ artigo/12989391.html>. Acesso em 25 set. 2012. 
o início a importância da educação como estratégia para o desenvolvimento da integração econômica e cultural do bloco, foi criado o Setor Educacional do Mercosul (SEM), cujas linhas de ação contemplam, entre outros objetivos, a difusão dos programas de intercâmbio existentes e a circulação do conhecimento através do setor educacional.

Para promover a mobilidade de estudantes, docentes e pesquisadores entre os países do bloco, foi lançado em 2006 o Programa de Mobilidade Acadêmica Regional para os Cursos Acreditados (MARCA), no qual os estudantes podem cursar um semestre acadêmico em uma Universidade de um país diferente do qual residem, recebendo no final do período o reconhecimento acadêmico das disciplinas cursadas na universidade de destino (http://programamarca.siu.edu.ar/).

Outra ação no âmbito do SEM é o Grupo de Trabalho sobre Políticas Linguísticas, que reúne especialistas dos diferentes países do bloco com o objetivo de discutir e propor ações de políticas linguísticas na Região. Dentre os objetivos da reunião de 2010, estão discutir a gestão da diversidade linguística e cultural nos países do bloco e repensar o status das línguas no contexto regional.

Dentre as iniciativas de caráter não-governamental no MERCOSUL, destaco a Associação de Universidades - Grupo Montevidéu (AUGM), organização civil formada por universidades da Argentina, Bolívia, Brasil, Chile, Paraguai e Uruguai. Criada paralelamente ao bloco em 1991, tem principal finalidade impulsionar o processo de integração através da criação de um espaço acadêmico comum. Entre suas atividades destacam-se o Programa ESCALA Estudantil e o Programa Mobilidade Pós-Graduação (esse criado em 2011), que promovem intercâmbio de estudantes respectivamente de graduação e pós-graduação no âmbito da AUGM, além do Programa ESCALA Docente, que consiste no intercâmbio de docentes e pesquisadores que fazem parte das universidades do Grupo Montevidéu. Outra ação no escopo da Associação é o Núcleo de ensino de espanbol e português como línguas segundas e estrangeiras, criado em 2006 com o objetivo de orientar ações, pesquisas e formação de professores na área de ensino de português e espanhol.

\section{POLÍTICAS BILATERAIS COM A ARGENTINA E AÇÕES PARA A FORMAÇÃO DE UMA REGIÃO BILÍNGUE}

Cabe apresentar brevemente algumas ações de políticas educacionais bilaterais entre Brasil e Argentina que, como já foi mencionado, tiveram um papel relevante no desenvolvimento do ensino de PLA e ELA no MERCOSUL. 
Em 30 de novembro de 2005 os governos argentino e brasileiro assinaram o Protocolo para a promoção e o ensino do espanbol e do português como segundas línguas, que oficializou o compromisso de implementar programas de formação de ensino de idiomas, e estabelecer um trabalho conjunto entre especialistas argentinos e brasileiros nas áreas de currículo, formação docente, educação a distância e elaboração de materiais didáticos, entre outros aspectos. $\mathrm{O}$ documento foi resultado de um longo processo de diálogo e ações entre os dois países desde a criação do MERCOSUL. Em 2004 o Certificado de Español - Lengua y Uso (CELU), desenvolvido através de um consórcio de universidades argentinas e brasileiras a partir da tecnologia do Celpe-Bras (já apresentado em seção anterior), já tinha sido aplicado pela primeira vez na Argentina. No ano de 2005, o Brasil promulgou a Lei N. 16.161, que torna o espanhol língua de oferta obrigatória no ensino regular (Ensino Médio) do país a partir de 2010. A Argentina, por sua vez, tornou o português língua de oferta obrigatória na escola secundária pela Lei N. 26.468 de 17 de dezembro de $2008^{30}$. Em 2007, reforça-se o compromisso entre os dois países através do Seminário BrasilArgentina, denominado Ensino e certificação do Português e do Espanbol como segundas línguas. O evento, cujo objetivo foi de estabelecer linhas prioritárias de ação e fornecer subsídios para auxiliar na tomada de decisões governamentais relativas ao PELSE (Português e Espanhol como línguas segundas e estrangeiras), reuniu professores e pesquisadores de universidades dos dois países. Nesse evento, foram discutidos o papel das universidades no ensino e difusão das duas línguas, a formação de professores, a elaboração de conteúdos, bem como a aplicação dos exames de proficiência em língua adicional Celpe-Bras e CELU.

\section{PROJETO ESCOLA INTERCULTURAL BILÍNGUE DE FRONTEIRA (PEIBF)}

Fruto de um acordo bilateral entre Brasil e Argentina, o PEIBF, criado em 2005 e inicialmente denominado Escolas Bilingues de Fronteira, tinha por objetivo inicial promover o intercâmbio entre professores brasileiros e argentinos para estreitar laços de interculturalidade entre cidades vizinhas através da implantação de um sistema de escolas bilíngues português/espanhol ao longo de toda a fronteira entre

30 Ao analisar o contexto das políticas bilaterais no Rio Grande do Sul e na Província de Córdoba, Cristofoli (2010), coloca em discussão os obstáculos que existem entre as políticas oficiais propostas e suas instâncias reais de implementação. A autora aponta inúmeros aspectos que afetam a execução das políticas bilaterais, entre eles, a falta de planejamento na execução das ações, a falta de professores e também os problemas de formação docente, para que seja possível efetivar as leis tanto no Brasil quanto na Argentina. 
os dois países ${ }^{31}$. O projeto inicial contou com 14 cidades, 7 em cada país. Em 2009, o projeto foi ampliado para outros países do Bloco, e conta atualmente com 28 escolas, em cinco países, distribuídas em 14 cidades-pares, conforme Morelo (2011) ${ }^{32}$.

A ideia é desenvolver um trabalho de educação intercultural com base em um modelo de ensino no qual os docentes elaboram e executam projetos de aprendizagem com os alunos, propiciando a esses a oportunidade de se comunicar nas duas línguas. Nesse intercâmbio docente, o professor "visitante" atravessa a fronteira uma ou mais vezes por semana, e vai lecionar em sua língua na escola do país vizinho. Cabe destacar que os professores não ministram aulas de língua, mas ensinam em português e espanhol, além de planejar juntos a divisão e a progressão das atividades do projeto no qual trabalham. O movimento de "cruce" tem gerado inúmeros aspectos positivos, entre eles o fato de expor os estudantes à língua adicional desde as séries iniciais, além de despertar nas crianças a curiosidade pela cultura do país vizinho e o estímulo para cruzar a fronteira.

Com a ampliação do projeto para outros países do MERCOSUL, novas experiências foram somadas ao PEIBF, tais como a das escolas de Sanja Puitã (Paraguai) e Ponta Porã (Mato Grosso do Sul), nas quais muitas crianças são falantes de guarani (algumas são monolíngues em guarani, outras transitam entre o guarani e o português, outras ainda entre o guarani, o português e o espanhol), incorporando ao projeto outras realidades presentes no complexo contexto multilíngue de fronteira, como descreve Morelo (2011).

Conforme a autora, os Ministérios (no Brasil, representado pelo MEC, e nos demais países por meio de coordenações locais ligadas aos Ministérios Provinciais e Secretarias de cada país) atuam nas escolas através de assessorias especializadas e contínuas, responsáveis por um conjunto de atividades como os planejamentos conjuntos e a formação docente. No caso do Brasil, o acompanhamento e a assessoria pedagógica têm sido realizados pelo Instituto de Investigação e Desenvolvimento em Política Linguística (IPOL) ${ }^{33}$, através de um trabalho de parceria com os

31 BRASIL. Ministério da Educação. Escolas de Fronteira. Brasília e Buenos Aires, março de 2008. Disponível em <http://portal.mec.gov.br/seb/arquivos/pdf/Escolafronteiras/doc_final.pdf $>$. Acesso em 20 set. 2012.

Este documento descreve, entre outros aspectos, as etapas de construção da relação de cooperação entre os dois países e como foi instituído o Programa até o ano de 2008.

32 MORELO, Rosângela. Linguística de Fronteira. Escolas Interculturais Bilingues de Fronteira: educando para uma cidadania ampla. 2011. Disponível em < http://seminariogelf.blogspot.com.br/p/linguistica-defronteira.html> Acesso em 20 set. 2012.

33 O IPOL é uma organização não-governamental brasileira sediada em Florianópolis, que tem prestado assessoria em diversas ações de política linguística. Site institucional: <http://www.ipol. org.br/>. 
demais países, no qual medidas são deliberadas e ações são sistematizadas de modo conjunto. Em julho de 2011 foi realizado I Seminário de Gestão em Educação Linguística de Fronteira no MERCOSUL (http://seminariogelf.blogspot.com/), que serviu de ponto de encontro a vários professores/gestores educacionais de fronteira para discutir, entre outras questões, as dificuldades enfrentadas para a manutenção do PEIBF e a complexidade linguística dos contextos de fronteira. Segundo Morelo, "o Brasil enfrenta o desafio de dar legitimidade ao Ensino Bilíngue no Sistema de Ensino Público", de modo que foi encaminhado ao Conselho Nacional de Educação (CNE) pelo MEC uma solicitação de reconhecimento da rede de escolas de fronteira e de definição de diretrizes para seu funcionamento.

\section{OBSERVATÓRIO DA EDUCAÇÃO NA FRONTEIRA (OBEDF)}

Dialogando com o Projeto Escola Intercultural Bilíngue de Fronteira, o OBEDF visa à educação linguística nos contextos de fronteira do Brasil com países hispânicos, focalizando a diversidade linguística nesses espaços e sua relação com o âmbito educacional e o entorno das comunidades envolvidas. Aprovado pela Capes em 2010, o projeto reúne três universidades (a UNIR, a UFSC e a UFAC) e cinco escolas de educação básica (duas em Mato Grosso, duas em Rondônia e uma no Acre), envolvendo seis cidades na região de fronteira Brasil-Bolívia e Brasil-Paraguai, além de 28 bolsistas de diferentes modalidades (iniciação científica, mestrado, doutorado, professor de educação básica e coordenador institucional). O OBEDF propõe-se a um trabalho de observação e sistematização do ensino nas citadas escolas de fronteira, além de propor um diagnóstico sociolinguístico nessas instituições (a cargo do IPOL), para construir um

espaço de compartilhamento de reflexões sobre o ensino das e nas línguas no processo de alfabetização. Seus resultados pretendem contemplar como o plurilinguismo está presente nas escolas, ponderando o que é importante levar em consideração para futuras políticas públicas ${ }^{34}$.

A partir de estudos de caso e da atuação conjunta de professores de ensino fundamental e pesquisadores acadêmicos, o projeto pretende "sistematizar modos de ensino da língua, identificar pontos de interferências e buscar soluções

\footnotetext{
34 ESTEFANO, Cristina; GHIZZO, Ana Maria. Seminário "Observatório da Educação na Fronteira" rompe com as barreiras da distância física, e reúne virtualmente os pesquisadores responsáveis pelo Projeto da UNISUL, UFSC e UNIR. Site do IPOL, 10 jun. 2011. Disponível em < http://www.ipol. org.br/imprimir.php? cod=686>. Acesso em 19 set. 2012.
} 
compartilhadas e viabilizadas pelas equipes locais ${ }^{1 / 35}$. Desse modo, o projeto visa contribuir para o estudo científico sobre os contextos educacionais nas regiões de fronteira, bem como estimular a produção conjunta de conhecimento sobre essa região ainda pouco explorada pelos estudos da linguagem no Brasil.

\section{UNIVERSIDADE FEDERAL DA INTEGRAÇÃO LATINO-AMERICANA (UNILA)}

Situada em Foz do Iguaçu (Paraná), na fronteira tríplice Brasil-ArgentinaParaguai, a UNILA fundamenta-se em uma política educacional bilíngue portuguêsespanhol voltada a questões do desenvolvimento latino-americano. Apoiada em uma proposta pedagógica inter e transdisciplinar que tem por diretriz promover a cooperação e o intercâmbio do conhecimento e da cultura entre os países da América Latina, a instituição conta com professores brasileiros e estrangeiros e recebe alunos de diferentes países latino-americanos (http://www.unila.edu.br). A universidade começou suas atividades em agosto de 2010, disponibilizando 300 vagas em seis cursos de graduação a quatro países: Brasil, Argentina, Uruguai e Paraguai. Em 2011, o processo de seleção foi ampliado, incluindo-se outros três países (Chile, Peru e Bolívia) e sendo oferecidas 600 novas vagas (com a criação de mais seis cursos de graduação, totalizando doze cursos). Atualmente, a UNILA conta com cerca de 1200 estudantes, que provêm de nove países latino-americanos (alem dos já citados, Colômbia e Equador aderiram em 2012) e distribuem-se em 18 cursos de graduação. Em fase de estruturação do nível de pós-graduação, a universidade ofereceu a partir de 2011 seus primeiros cursos de especialização.

A instituição constituiu um ambiente multilíngue no qual a maioria das práticas desenvolve-se em português e espanhol, línguas oficiais da proposta educacional, mas com a copresença de outros idiomas, como o guarani, o quéchua e o aimara, o que faz da universidade um lugar singular de encontro das línguas. Outro aspecto relevante nesse cenário é a diversidade cultural: as salas de aula são ponto de encontro não apenas de línguas diversas e suas variedades, mas também de diferentes formações socioculturais, constituindo um espaço educacional complexo, no qual as práticas de ensino/aprendizagem envolvem diferentes históricos escolares e de letramento.

35 OBDEF. Observatório da Educação na Fronteira. Boletim Informativo. Ano 1, Edição 1, Nov. 2011, Florianópolis. 


\section{CURSO DE ESPANHOL-PORTUGUÊS PARA INTERCÂMBIO (CEPI)}

O CEPI é resultado do trabalho de uma equipe interinstitucional e interdisciplinar de pesquisadores e professores de Português e Espanhol como línguas adicionais e de Educação a Distância (EAD) de uma universidade brasileira, a Universidade Federal do Rio Grande do Sul (UFRGS), e duas argentinas, a Universidad Nacional de Cordoba (UNC) e a Universidad Nacional de Entre Ríos (UNER).

Iniciado em 2007, é uma ação de política linguística que tem por objetivo promover a integração nos países do bloco através da inserção em práticas sociais e acadêmicas de alunos participantes de programas de mobilidade acadêmica no MERCOSUL e América Latina. São oferecidos aos intercambistas dois cursos de línguas adicionais, um de espanhol e outro de português, sendo que os materiais do CEPI de cada universidade são adaptados para o contexto local de cada Instituição (BULLA, GARGIULLO \& SCHLATTER, 2009). O projeto inclui também o Curso de Formação de Professores CEPI (CFP-CEPI), cujo objetivo é de preparar docentes para atuar com base no construto teórico do curso (SCHLATTER et al., 2009b) e elaborar materiais didáticos para a criação de seus CEPI institucionais. Realizado em ambientes digitais, o CFP é um requisito para as universidades que queiram oferecer o Curso.

O trabalho interinstitucional do CEPI tem possibilitado trocas entre professores e pesquisadores das universidades envolvidas, favorecendo a exploração de novas metodologias, recursos didáticos e tecnológicos para o ensino de línguas a distância.

\section{DICIONÁRIO TRILÍNGUE ESPANHOL-PORTUGUÊS-GUARANI}

Elaborado pelos linguistas Domingo Aguilera (Fundação Tapé Avirú) e José Maria Rodrigues (Universidade Católica Nossa Senhora de Assunção), o Dicionário Trilíngue español-português-guarani foi publicado com o apoio da Embaixada do Brasil em Assunção $^{36}$ e da Fundação Tapé Avirú Paraguay e apresentado ao público no ano de 2011. O dicionário foi produzido com base no Projeto Avakotepa, cujo objetivo é a constituição de um corpus oral e escrito da língua guarani contemporânea, e sua disponibilização à comunidade científica para fins de pesquisa no que concerne à

36 A Embaixada Brasileira em Assunção tem apoiado diversas ações na área de difusão da língua e cultura brasileiras, principalmente as desenvolvidas pelo Centro Cultural do Brasil naquela cidade. 
fonologia, morfologia e sintaxe da língua guarani falada no Paraguai ${ }^{37}$. De acordo com o blog do Projeto, "o dicionário implica uma ruptura com a lexicografia tradicional da língua guarani. Trata-se do primeiro dicionário intercultural do MERCOSUL que reconhece a autonomia da língua guarani em igualdade de status com as outras línguas oficiais do bloco, o espanhol e o português" ${ }^{38}$ Além de constituir-se como instrumento relevante na promoção do status da língua guarani no contexto de integração do MERCOSUL, o dicionário visa contribuir para enriquecer a área de linguística de corpus e produtos linguísticos feitos com base nos idiomas falados no bloco. Destina-se a estudantes, professores, pesquisadores, diplomatas, e público em geral que desejem aprender a língua guarani.

\section{CONSIDERAÇÕES FINAIS}

Com as mudanças sócio-históricas vividas nas últimas décadas e com o desenvolvimento da globalização econômica e tecnológica, assistimos ao surgimento de novas formas de organização da vida contemporânea nas quais as fronteiras políticas, econômicas e culturais já não se restringem aos limites das fronteiras físicas nacionais. Nesse novo paradigma, a comunicação, a linguagem e o discurso ocupam um lugar de extrema relevância por estarem tanto no cerne das relações produtivas quanto ligadas à construção da identidade social, cultural e política dos indivíduos. Como consequência disso, o multilinguismo vem ganhando cada vez mais importância nas diferentes esferas do mundo contemporâneo, de modo que atores sociais diversos e também o Estado passam a questionar a ideologia monolíngue. Assim, as línguas e seu gerenciamento vêm ocupando papel central no mundo todo, de modo que governos e outros atores sociais têm investido cada vez mais em reformas no ensino, elaboração de novos currículos, oficialização de novas línguas, financiamento e elaboração de bancos de dados de línguas, entre outras ações.

Na América Latina, e especialmente no âmbito do MERCOSUL, as ações apontam para uma valorização do ensino de línguas adicionais como relevante para a formação profissional e tecnológica. Em outras palavras, parece formar-se uma visão do ensino de línguas adicionais como campo fértil para a formação de capital simbólico, tanto num plano mais amplo, o econômico, quanto num plano mais

37 Blog do Projeto Avakotepa: <http://avakotepa.blogspot.com/>. Acesso em 25 set. 2012.

38 RODRIGUES, José Maria. Avakotepa. <http://avakotepa.blogspot.com/>. Publicado em 30/05/2011. Acesso em 27 set. 2012. 
restrito, de formação dos sujeitos/cidadãos. O contexto do bloco, por conta das ações de cooperação geradas, cria demandas que estimulam a aprendizagem das línguas, colaborando para a manutenção de uma dinâmica entre demandas e ações que, por sua vez, serve de estímulo à criação de iniciativas de política linguística por parte do Estado e de outros atores sociais. Ou seja, ações e demandas se correlacionam e se retroalimentam, assim como produzem reflexos no ensino, na aprendizagem e também no gerenciamento das línguas na Região. Outra marca dessa dinâmica é a reciprocidade de ações, que estabelece uma cadeia de compromissos mútuos entre países e organismos, como é o caso das relações bilaterais entre Brasil e Argentina, construídas desde a criação do MERCOSUL.

No Brasil, em função do crescente destaque político e econômico do país nos cenários Regional e mundial, um aumento considerável do público estrangeiro em aprender a língua portuguesa nos últimos anos tem se evidenciado principalmente através do incremento no número de acordos educativos assinados pelo governo brasileiro com outros países, e de convênios assinados entre universidades brasileiras e estrangeiras. Quanto às políticas de difusão internacional do português, evidenciase um maior protagonismo nas ações de promoção da língua, entre as quais se destaca o Celpe-Bras, um instrumento de avaliação cujo efeito retroativo faz-se sentir na maneira de ensinar e aprender português como língua adicional, além de simbolizar um instrumento que ressignifica o lugar da língua brasileira no mundo e a forma como o português é visto dentro do país, pelos próprios brasileiros.

A nova perspectiva de valorização dos contextos multilíngues parece promover também uma nova visão da relação entre línguas, contribuindo para a construção de uma consciência multilíngue, que destaca positivamente o convívio com outras línguas. No caso do Mercosul, não se trata apenas do processo de redimensionar o espaço de cada língua, mas também da concepção que os falantes têm delas e da forma como esses se relacionam entre si. Além do benefício significativo do contato com a língua e a cultura do outro - que pode se constituir como um espaço de ampliação da atuação dos sujeitos - há também, em termos de políticas linguísticas internas, o de ajudar a repensar a nossa "política do monolinguismo" (que tem sido historicamente tão eficiente na exclusão das demais comunidades linguísticas brasileiras), ao deslocar o eixo da "língua única" e nos colocar em contato com modos de pensar diversos.

Neste artigo buscou-se apresentar algumas das ações políticas de difusão internacional da língua portuguesa, com foco nas iniciativas no âmbito do MERCOSUL nas áreas de ensino, pesquisa e avaliação de proficiência. Sendo a organização social pautada também e principalmente por valores linguísticos, 
as políticas linguísticas são consideradas importantes instrumentos de análise e intervenção nas relações linguísticas e, consequentemente, identitárias, culturais, sociais e políticas entre os indivíduos. Desse ponto de vista, espera-se que as políticas linguísticas estejam cada vez mais a serviço da diversidade linguística e cultural que compõe não apenas o MERCOSUL, mas o próprio Brasil, para ajudar a produzir a integração de diferentes culturas e formas de produzir conhecimento e, assim, ampliar o acesso, pelos sujeitos, a práticas sociais em diferentes línguas.

\section{REFERÊNCIAS BIBLIOGRÁFICAS}

BALDAUF JR, R. (2006). Rearticulating the Case for Micro Language Planning in a Language Ecology Context. Current Issues in Language Planning, v.2, n.7, pp. 147-170.

BRASIL. MINISTÉRIO DA EDUCAÇAO E CULTURA. Secretaria de Educação Superior (2006). Certificado de Proficiência em Lingua Portuguesa para Estrangeiros: Manual do Candidato. Brasília: MEC.

BRASIL. MINISTÉRIO DAS RELAÇÕES EXTERIORES (2011). Balanço de política externa 2003-2010. Brasília: MRE. Disponível em <http://www.itamaraty.gov.br/temas/ balanco-de-politica-externa-2003-2010>. Acesso em 28 set. 2012.

BULLA, G.; GARGIULO, H.; SCHLATTER, M. (2009). Organización general de materiales didácticos para la enseñanza online de las lenguas: el caso del Curso de Español-Portugués para el Intercambio (CEPI). II Jornadas Internacionales de Tecnologías Aplicadas a la Enseñanza de Lenguas. Universidad Nacional de Córdoba, Córdoba, 2009, v. CD. p. 01-12.

CALVET, L. (2007). As políticas linguísticas. São Paulo: Parábola.

CARVALHO, S.; SCHLATTER, M. (2011). Ações de difusão internacional da língua portuguesa. Cadernos do IL. Porto Alegre, no. 42, pp. 260-284.

COOPER, R. (1989). Language planning and social change. Avon: Cambridge University Press.

COSTA, E. V. Formação em serviço de professores de português como língua adicional. Pesquisa em andamento (Mestrado em Linguística Aplicada). Instituto de Letras, UFRGS, Porto Alegre, RS.

CRISTOFOLI, M. S. (2010). Políticas de línguas estrangeiras na educação básica: Brasil e Argentina entre avanço, percalços. Tese de Doutorado em Educação. Faculdade de Educação, UFRGS, Porto Alegre, RS.

DINIZ, L. A. (2010). Mercado de línguas. A instrumentação brasileira do português como língua estrangeira. São Paulo: RG Editora.

(2012). Política linguística do Estado brasileiro na Contemporaneidade: a institucionalização de mecanismos de promoção da língua nacional no exterior. Tese Doutorado em Linguística. Instituto de Estudos da Linguagem, Unicamp, Campinas. 
FARACO, C. A. (2008). A lusofonia: impasses e perspectivas. Conferência no Simpósio Políticas e ideologías en la legitimación de las lenguas internacionales. $8^{\circ}$ Congreso de Lingüística General da Universidad Autónoma de Madrid.

FOREQUE, F. Português é POP. Folha de São Paulo, São Paulo, 16/10/2011. Disponível em $<$ http://acervo.folha.com.br/fsp/2011/10/16/10 > . Acesso em 20 de jun. 2012.

GARCÍA, O.; MENKEN, K. (2010). Stirring the onion: educators and the dynamics of language education policies. In: (eds.). Negotiating language policies in schools: educators as policy makers. New York: Routledge, pp. 249-261.

HAUGEN, E. Linguistics and Language Planning (1966). In: BRIGHT, W. (Org.). Sociolinguistics. La Haye: Mouton.

HORNBERGER, N. (2006). Frameworks and Models in Language Policy and Planning. In: RICENTO, T. (ed.). An introduction to language policy: Theory and method. Oxford, Blackwell Publishing, pp. 10-23.

KAPLAN, R.; BALDAUF, R. (1997). Language Planning from Practice to Theory. Reino Unido: Multilingual Matters.

LEWIS, M. P. (ed.) (2009). Ethnologue: Languages of the World, Sixteenth edition. Dallas, Tex.: SIL International. Disponível em < http://www.ethnologue.com/ethno docs/ distribution.asp? by=size $>$. Acesso 10 jun. 2012.

LI, Ye. (2009). Pressupostos teóricos e culturais para um curso de preparação para o exame Celpe-Bras para alunos chineses. Dissertação de Mestrado em Letras. Instituto de Letras, UFRGS, Porto Alegre.

MARTÍN, M.; BEDINELI, T. Brasil de oportunidades faz curso de português "bombar". Folha de São Paulo, São Paulo, 05/08/2012. Disponível em < http://www1.folha.uol. com.br/cotidiano/1131953-brasil-de-oportunidades-faz-curso-de-portuguesbombar.shtml >. Acesso 20 ago. 2012.

OLIVEIRA, G. M. (2004). Política Linguística, Política Historiográfica: Epistemologia e escrita da História da(s) Língua(s) a propósito da língua portuguesa no Brasil Meridional (1754-1830). Tese de Doutorado em Linguística. Universidade Estadual de Campinas, Campinas.

(2010). O lugar das línguas: A América do Sul e os mercados linguísticos na Nova Economia. Synergies Brésil, nº spécial 1, pp. 21-30. Disponível em < http://ressourcescla.univ-fcomte.fr/gerflint/BresilSPECIAL1/gilvan.pdf>. Acesso 25 ago. 2012.

RICENTO, T. (2000). Historical and theoretical perspectives in language policy and planning. Journal of Sociolinguistics, vol. 4, n. 2, pp. 196-213.

(2006). Theoretical perspectives in language policy: an overview. In:

(ed.). An introduction to language policy: Theory and method. Oxford: Blackwell Publishing, pp. 3-9.

SCARAMUCCI, M.V.R. (2006). O exame Celpe-Bras: impactos nas percepções de professores e candidatos em contextos de PLE. In: Congresso Internacional de Política Linguística na América do Sul. Língua(s) e povos: unidade e diversidade. João Pessoa: Ideia, pp. 270-276. 
SCHLATTER, M. (2006). O sistema de avaliação Celpe-Bras: características, implementação e perspectivas. In: Congresso Internacional de Política Linguística na América do Sul. Lingua(s) e povos: unidade e diversidade. João Pessoa: Ideia, pp. 171-175.

SCHLATTER, M.; GARCEZ, P. M. (2009). Línguas adicionais (Espanhol e Inglês). In: RIO GRANDE DO SUL, Secretaria de Estado da Educação, Departamento Pedagógico. Referenciais curriculares do Estado do Rio Grande do Sul: linguagens, códigos e suas tecnologias. Porto Alegre: SE/DP, pp. 127-172.

SCHLATTER, M.; SCARAMUCCI, M.; PRATI, S.; ACUÑA, L. (2009). Celpe-Bras e CELU: Impactos da construção de parâmetros comuns de avaliação de proficiência em português e espanhol. In: ZOPPI FONTANA, M. (org.). O português do Brasil como lingua transnacional. Campinas, SP: Editora RG, pp. 95-122.

SCHLATTER, M.; BULLA, G.; GARGIULO, H.; JURIC, V. (2009b). La Formación del profesor CEPI para interactuar en una comunidad colaborativa de aprendizaje a distancia. II Jornadas de Tecnologías aplicadas a la Enseñanza de las Lenguas. Universidad Nacional de Córdoba, Córdoba, v. CD. p. 18.

SHOHAMY, E. (2006). Language policy: bidden agendas and new approaches. Reino Unido: Routledge.

ZOPPI FONTANA, M. (2009). O português do Brasil como língua transnacional. In: (org.). O português do Brasil como língua transnacional. Campinas: Editora RG, pp. 13-41

Recebido: 09/10/2012

Aceito: 25/10/2012 